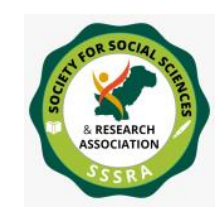

\title{
IMPACT OF SOCIAL MEDIA ON NATIONAL SECURITY IN THE FACE OF GLOBALIZATION: PAKISTAN'S PERSPECTIVE
}

Dr. Muhammad Asim, Chairman, Karachi University Business School, University of Karachi, Karachi, Pakistan

Email: masimku@hotmail.com

Hashmat Ali, PhD Scholar, Department of Management Sciences, Bahria University, Karachi - Pakistan, e-mail: hashmatkhanpn@gmail.com

\begin{abstract}
Internet usage in Pakistan has been growing exponentially in terms of access, subscriptions and roll-out-of-content and services coupled with the recent mobile broadband innovations. Facebook is considered the most popular social platform, with Google the second followed by Twitter and Instagram (Yusufzai, 2016). In Pakistan over 30 million people are registered internet users out of which, 15 million get access to internet through cellular devices. Over 155,000 Pakistanis have Twitter accounts, whereas the number of Facebook users is considerably higher at 15 million. Social media has been gaining vast popularity among the masses. Cheap mobile broadband coupled with inexpensive smart phones is adding to this number rapidly.

People are inclined towards social media to easy and cheap way to spread their opinions, share experiences, offer suggestions and give feedback on topics of common interest. It has led to a massive rise in both positive and negative activities. The Government of Pakistan has certainly taken into account this issue and has taken some meaningful steps and hopes to do more in this sector to curb the unlawful and illegal acts and get a control over it.
\end{abstract}

The study explores the pros \& cons of social media and its impact on the national security in the global arena. It suggests the way forward for the 


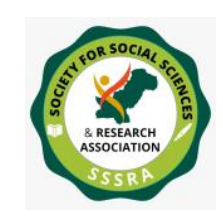

Pak. Journal of Int'L Affairs, Vol 2, Issue 1 (2019)

Impact of Social Media on National ......

governments and general public to accrue most of the benefits and thwart ill designs of hackers, terrorists and extremists who want to use it against the humanity.

Keywords: Social Media, Facebook, LinkedIn, Twitter, Instagram, Terrorists, Extremists

\section{INTRODUCTION}

In the past decade, usage of internet in the country has been gaining momentum in terms of access, subscriptions and roll out of content and services. Introduction of high speed internet and the recent introduction of mobile broadband have put the internet influx into the urban and rural areas on the fast track.

According to recent social media usage statistics of Pakistan, Facebook is the most popular social platform/website which handles more than 3 billion connections per day. Google is the second most accessed website in the country with over 2.5 billion connections per day. Twitter and Instagram are also among the toppers in the list of most online hits per day (Yusufzai, 2016). Those calculations are, however, from a global point of view. Focusing on our homeland, we can see that the current population of Pakistan is 192,532,929 (Based on the latest United Nations estimates as of Monday, June 6, 2016) with about $38.6 \%$ of the population being urban (74,986,621 people in 2016). With that being said, there are over 30 million people who are registered internet users and out of which, 15 million access the internet through their cellular devices. Furthermore, research has indicated that over 155,000 Pakistanis have Twitter accounts, whereas the number of Facebook users is considerably higher at 15 million registered users.

Social media has been gaining vast popularity among the masses in Pakistan mainly due to Facebook, Twitter, Skype, Instagram etc. The introduction of mobile broadband coupled with the influx of affordable smartphones had a catalytic effect on the use of social media in Pakistan. 


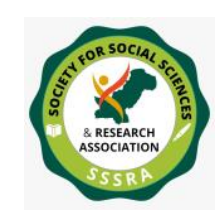

Pak. Journal of Int'L Affairs, Vol 2, Issue 1 (2019)

Impact of Social Media on National ......

People turn towards social media to voice their opinions, experiences, suggestions and feedback on any topic or constituent of the society.

Social media has been one of the fastest growing platform in the world where people take refuge to voice their opinion when it is not possible for them to do it any other way; and with an unparalleled rise in the number of users of platforms like Facebook, LinkedIn, and Twitter etc., it has led to a massive rise in both positive and negative activities.

With the help of social media, in the context of Pakistan, terror acts have been on the rise. From the San Bernardino Bombing in December 2015, to people indulging in terrorist groups like Tehreek-e-Taliban Pakistan, and Daesh, many people have been fleeing to the warzones of Syria and Iraq to indulge themselves in those terror acts. The people willing to be part of such acts are contacted through social media and instructed on what they need to do and how they need to do it. However, Governments and security forces track the activities taking place on social media and so far, have arrested hundreds of people for having linked to the promotion of militancy online. Some accounts may go unnoticed by the Governments, but to humanities' fortune, these terrorists' social media acts do not go unchallenged. Hacktivist groups such as 'Anonymous' have took it in their own hands to fight these militant groups on the web platform by hacking into several militant's twitter accounts and suspending them. Many others have overloaded the militants' physical servers by hacking into them, causing it to shut down, or better yet, destroyed. Due to the efforts of such hacktivist groups, several terrorist attack attempts have been traced and prevented.

Another one of the horrendous and dreadful acts through social media is Cybercrime--Identity theft and cyber-bullying. People who use social media platforms have updated their information on these websites with their privacy being as minimum as possible, which makes them an effortless target for hackers; and as they operate their e-banking through the same devices while using their social media accounts and clicking on links that they don't know much about, hackers find it easy to hack into their bank accounts and use their money or steal it. As information is 


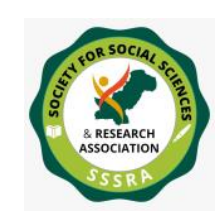

Pak. Journal of Int'L Affairs, Vol 2, Issue 1 (2019)

Impact of Social Media on National ......

posted online with viewers being both close friends and strangers, this also leads to blackmailing and harassment in the form of cyber bullying when strangers get a hold of something personal of another person using the platform. Cases such as these tend to go unreported as children are hesitant to inform their elders about any such activity for multiple reasons. Another of these criminal activities is the fraud happening through job adverts where job seekers are offered jobs where they are unaware that the job being offered to them is nonexistent and in return, they are required to pay an amount in the form of registration fees. The Government of Pakistan has certainly taken into account this issue and has taken some meaningful steps and hopes to do more in this sector to stop these acts and get a control on these acts and have foiled multiple plans.

With that being said, social media not only has a negative side, but a positive one as well, as every coin has two sides; the use of social media has led to many positive impacts on the society as well. It has helped the government to connect with the common man in ways that were not possible before social media became common and as easily accessible as it is nowadays. Our Government can also use the social media to segment the citizens according to the message they want to deliver to other people. Along with this, there have been several efforts going on to work on the ehealthcare facilities to have them well-established in our society, with the help of which, Government of Pakistan can keep a track of citizens' medical records and provide better health provisions to its citizens.

In extreme cases, such as controlling and managing the aftereffects of WMD usage, social media might prove very helpful in spreading awareness and handling the disturbance and panic that will overtake the society.

Although many of the measures discussed in the positives of social media are yet to be accomplished by the Pakistan government, but these measures provide a benchmark and something to start off with to our government once it decides to bring into use this gift of technology for the betterment of the citizens of Pakistan. We remain hopeful in this regard for terrorism is one of Pakistan's most dangerous and emphasized problems 


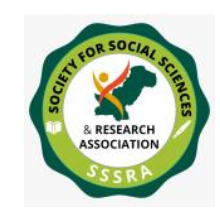

Pak. Journal of Int'L Affairs, Vol 2, Issue 1 (2019)

Impact of Social Media on National ......

and with the recent positive results of the efforts from the government and the military institutions for getting rid of this mess a Pakistani can certainly be positive that our institutions will achieve results on the virtual platform like they have managed to on the physical landscape.

\section{SOCIAL MEDIA AND TERROR ACTS}

"With great power comes great responsibility"- this is a saying that we hear every once in a while, but it has more meaning to it than what meets the eye. Social media may not always be used the way its inventors thought the world would. People manipulate it in accordance to their means.

According to an article posted on April 27, 2016, a man had been arrested for uploading Facebook posts that contained literature supporting banned terrorist organizations as well as denouncing the security forces. According to Counter Terrorism Department of Pakistan, the suspect was arrested during a raid in Abbottabad and had been accused of sharing provocative content from his Facebook account against his own homeland for a long period of time. This is one of the many cases seen in Pakistan and around the world, many of which have not been noticed by the forces yet (Man arrested for supporting banned outfits on social media, 2016).

Another case was recently seen in Spain where a man had allegedly supported various terrorist groups, operating in the conflict zones of Syria and Iraq, and promoted militancy through the only weapon he yet had gotten a hold on, his social media accounts. He was arrested from his residence on May 29, 2016. According to Dawn News, Spain has so far detained 24 people under the suspicion of having links with militancy including 14 people belonging to terror groups allegedly glorifying terror acts on Facebook and Twitter (Reuters, 2016).

These are, however, not the only cases where people tirade all day about how they are averse to the system that they live in. On one hand, some cases are harmless as indulging in politics is a familiar fuss for the people of Pakistan. On the other hand, there are other cases that are not only 


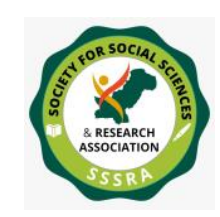

Pak. Journal of Int'L Affairs, Vol 2, Issue 1 (2019)

Impact of Social Media on National ......

destructive but also go unnoticed. With the proliferation of social media, one would wonder how our privacy may be secured and our data be concealed. However, sacrificing our privacy may be the only way to conserve our national security. Militants of banned organizations around the world have come to social media to bring together the people who support their cause to be as helpful as they can be.

It is no revelation that where the fight about subjectivity lies among the people who have disparate views regarding what is right and what is wrong, people have taken matters to a platform that is not only globally heard but also responded to, if the forums chosen are in accordance with their needs. Militant organizations have gotten a hold of how people think and they respond accordingly. They reach out to people through the same platform that people use to express themselves and their opinions and have successfully recruited thousands of people, many of whom have carried out attacks in their own homeland. The recruiters may not be as true to their words as the recipients of their messages may think they are, but they hit the right spot that makes people believe them as well as support their actions. With that being said, the people at fault in such situations are not only the terrorists that take such steps, but also the people who are naïve and gullible enough to believe them by cutting off connections with their logical thinking. As these activities happen on the internet through social media platforms, what our government can do is keep an eye out for such conversations. Staying alert about the activities that take place on social media can stop such terror incidents. It may not be easy to completely stop them, but it is not beyond the bounds of possibility to at least bring them down to a much smaller scale substantially.

In December 2015, a woman along with her husband carried out a mass shooting and an attempted bombing in Bernardino, California, which resulted in terrible casualties with 14 citizens dead and 12 seriously injured. They targeted a San Bernardino County Department of Public Health training event which they had reportedly been plotting for months and had discussed the plot with their relatives back in Pakistan through Facebook messaging and private chats. The woman had gone through three security background checks before she was granted her US visa, i.e. 


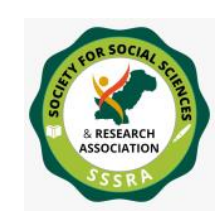

Pak. Journal of Int'L Affairs, Vol 2, Issue 1 (2019)

Impact of Social Media on National ......

permission to enter the United States of America; yet if those security checks had been conducted on her social media accounts, that would not have been the case. Her social media hatred for the country that she had applied to visit had gone absolutely unnoticed, which led to such a mass shooting incident, leaving many killed or injured, but most importantly, that incident left a scar in the minds of the people. Had they gone through or even given a glimpse to her social media, it would have been prevented. Even though they were not directed by any terrorist organization, they had become radicalized over several years prior to the attack and had expressed their commitments to the jihadi groups through private messaging (Haider, 2015) (Engel, 2015). As the days went by, the number of twitter tweets and Facebook posts increased. Some people condemned the incident; others were in favor of it. The people in favor took it upon themselves to spread their opinions regarding how right the woman and her husband were. Such cases not only harm the people who have witnessed them but also the image of the country of the terrorists' nationality. Publishing hate content should never be taken as lightly as it is. Such series of events lead to secretive planning to torment the people who do not hold the same viewpoint as them, which puts our national security at risk.

Humanity's dependence on social media for reasons being countless has led to an increase in the activities of militant organizations by reaching out to their supporters and redeem their services is not considered to be unusual any longer.

ISIS militants cultivate vulnerable recruits with sympathetic messages, and engage them via secure messaging services. Recruiters will occasionally ship gifts to the targets - and sometimes, even an airline ticket. If the recruit cannot travel, they are encouraged to launch terror attacks at home (Singer \& Brooking, 2015).

Every now and then, people from around the world have been fleeing to Syria and Iraq to join the battlefield and fight the war against the forces that are trying to rid the country of the current most lethal militant group self-proclaimed Islamic State (Better known to the world as 'ISIS' or 


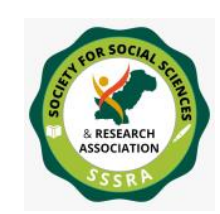

Pak. Journal of Int'L Affairs, Vol 2, Issue 1 (2019)

Impact of Social Media on National ......

'Daesh'). The people who cannot do so do not get left behind. Through conversations via various forums, they are given guidance on what they need to do to carry out the attacks at home (Singer \& Brooking, 2015).

Taking into considering one case where a British woman had been found guilty and arrested for taking her toddler to Syria to join ISIS earlier this year in January, it may be easier to understand how matters have simply gone out of hand. The woman had fled to Syria in the October of 2014 taking her toddler with her but came back and claimed that she had realized that she had made a mistake. Following her court trials, she had denied charges, however, the jury did not believe her account after seeing multiple tweets, messages and photographs, including images of the black flag of ISIS and passages calling on people to take up arms and stating her wish to become a 'martyr' on her social media accounts (Mortimer, 2016).

Where thousands of people from different parts of the world have taken off to join various militant groups located in different parts of the globe, there are hundreds of Pakistanis who have, in one way or another, either done the same or have been supporting the terrorist activities while sitting behind a computer screen, plugged to an internet connection.

Where the war has been taken up on a horde of forums and blogs, the same platform is used to win the battle against such terrorist organizations through which hundreds of attacks have been averted. With threats mounting, an unusual alliance has begun to fight back against the militant groups' social-media war (Singer \& Brooking, 2015).

Hackers use tens of thousands of linked computers (botnets) to overwhelm ISIS websites, sometimes burning out their physical servers. As the online hacktivist group 'Anonymous' declared war on ISIS, they took down around 5,500 twitter accounts belonging either to the militants or to people who have been linked to promoting militancy through their tweets (Ohlheiser, 2015). This online platform has also been used to locate the militants recruiting people for their means all the while operating from different parts of the world. Posing as potential recruits, hackers slowly gather data about their ISIS recruiters, using cyber forensics to identify 


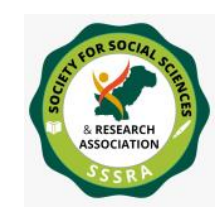

Pak. Journal of Int'L Affairs, Vol 2, Issue 1 (2019)

Impact of Social Media on National ......

and locate specific individuals. This information is then revealed to the world and passed to local authorities. One such tip, discovered by the hacktivists of Ghost Security, helped avert a July terror attack in Tunisia. Hackers plunge into the deep Web, beyond the reach of normal search engines, to find and eliminate ISIS recruiting centers and bitcoin donation pages. In one instance, the Ghost Security Group (not to be confused with Ghost Security) replaced an ISIS propaganda hub with an advertisement for Viagra and Prozac (Singer \& Brooking, 2015).

Google, Twitter, and Facebook - platforms intended for free and unfettered speech-have truculently revised their terms of service to ban content that promotes militancy. Google's YouTube now deputizes some human-rights groups as "trusted flaggers" to identify ISIS content; Twitter has banned "indirect threats of violence"; Facebook proactively removes known militants from its servers (Singer \& Brooking, 2015).

Though Governments may not yet have found many ways to tackle the situation at hand, they have at least figured out how to keep some of the troubles at bay.

\section{CYBERCRIME}

Social media is, however, not only a platform that is a constant war between the people and militants; it can also be used for cybercrime. There have been reportedly over thousands of such cases which have led to depression for many individuals.

Cybercrime may be defined as 'criminal activities carried out by means of computers or the Internet.' Those criminal activities may include hate crimes, telemarketing and Internet fraud, identity theft and credit card account thefts.

Sharing your information, interests or plans, there may not be much harm in that; but if you happen to use that same device while handling your bank accounts, you're only making it easier for your information that is 


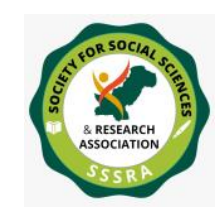

Pak. Journal of Int'L Affairs, Vol 2, Issue 1 (2019)

Impact of Social Media on National ......

much personal than the name of book you are reading or the movie you are planning to watch in the coming week. Even then, if we take some precautions, it may not be as easy for information to be stolen. However, we are the ones make it easier for hackers. People share their personal information, their contacts, the places they've been to, as well as the place that they are planning to go. If we look at it, it has no harm on us, but on a bigger scale, it is doing more harm to our national security than good. Recent research reveals that identity theft affects millions of people a year, costing victims countless hours and money in identity recovery and repair.

According to 'Javeline Strategy and Research Report', 68 percent of people shared their birthdays, 63 percent of people shared the name of the high school they attended, 18 percent shared their phone numbers and 12 percent shared their addresses on social media and their profiles with their profiles set on public (Cullina, 2012). People who give away far too much personal information on social media are usually the victim of identity theft. Identity fraud gives lawbreakers and terrorists the instruments they have to stay mysterious, obtain entrance, maintain a strategic distance from identification, and exchange assets. There are numerous sorted out wrongdoing bunches far and wide executing various savage and offensive wrongdoings, the greater part of which are upheld by character misrepresentation.

As social media accounts are set as public, it is visible for any person to view as well as steal your personal information to use it without any hesitation for their own means. What a person should be afraid of is that they do not have to know you personally for to do so anymore. Your cyber possessions can be used against your own self. It is no doubt quite challenging these days to combat such threats and to find innovative approaches to tackle with such social threats. Cyber bullying is more likely than other forms of bullying to go unreported to parents and administrators. When little children face situations where they are bullied on the social media, they keep it to themselves and do not share the problem with their parents or guardians, fearing that their computers or cellular phones would be taken away from them. Being little and not understanding the world as much as their parents, they do not understand 


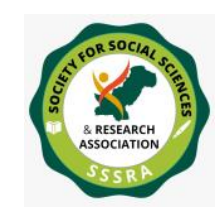

Pak. Journal of Int'L Affairs, Vol 2, Issue 1 (2019)

Impact of Social Media on National ......

that what is being done is for their own safety and not sharing the problems of cyber bullies only makes matters worse.

Dealing with the problems that are brought about by social media may be some recent difficult tasks that we have begun to face but what is more important is to judge the risks and threats associated with it because it is our utmost responsibility to provide a secure environment that does not affect individuals or nation as a whole.

Whereas social media is not a new method for acquiring information from users, another method that is widely used for the purpose of identity theft is when users are directed to a webpage that seems authentic, where they end up sharing their personal information. Over half a decade ago, some students at Indiana University published an article titled "Social Phishing" which promulgated the concept if phishing migrating from your email inbox to your social networking sites or vice versa. Phishing occurs when a party contacts you to follow a link which actually directs the individual to a fraudulent website or messages that appear legitimate and asks the user to provide personal information. In one study, Indiana University students discovered that being part of one's social circle of friends allowed a cybercriminal to harvest large amount of reliable information. Thus, it can be said that criminals can use Social Networking Sites as a way to gain higher level of information.

While there may not be authentic processes through which genuine social media accounts may be determined, one should ensure that their online social circles only consist of the people they know and have conversed with personally.

Social media is a threat to different companies as well because what employees disclose on their accounts can have an impact on the company's image. According to the 'World Economic Forum, Global Risks 203 Report', there have been so many incidents reported in past years where false information transmitted from social networking sites created serious consequences. The rapid spread of false information through social media is among the emerging risks. No company can afford 


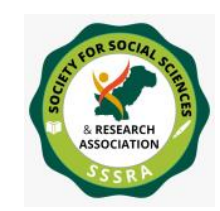

Pak. Journal of Int'L Affairs, Vol 2, Issue 1 (2019)

Impact of Social Media on National ......

to ignore the unprecedented reach of social media due to the negative effects it can have on their business. Those companies that recognize the threat and value of social media have demonstrated that success is achieved through empowering staff to undertake social media on behalf of the organization with the help of policies backed up by continual training and also by the analysis of the information shared on social media by employees.

In the year 2011, Canada suffered a significant security breach because of penetration of computer systems of three key federal government departments. The hackers got an opportunity to steal highly sensitive documents and because of this hacking the departments had to stop working for months. The Canadian Government claimed that sharing of personal information on the social media had contributed much to this situation as privacy protection and cyber security are thought to be interconnected (Weston, 2011).

Another mistake that many people have made was sharing their future vacations plans with their social media connections along with their residential address. This opens up doors for thieves to keep an eye on your activities until you leave for your flight and then rob your possessions without being afraid of getting caught during or after the act.

Believing the contents posted on social media is hardly a rare act for the people of Pakistan. That may have to do with their desperation to find what they are seeking or just for the sake of curiosity. No matter the case, Pakistan has seen numerous criminal acts conducted over social media. Many of which have been caught and reversed and many are still on the loose.

During the autumn of 2014, Federal Investigation Agency (FIA)'s Cybercrime Circle of the Rawalpindi region had arrested four suspects who had allegedly swindled and collected around Rs 200 million from people who had been offered jobs on advert clicking websites. Through such fraudulent schemes, frauds profess to be legal businessmen offering jobs to job seekers, be it fulltime or part-time. To move ahead with these 


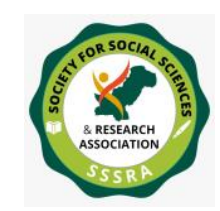

Pak. Journal of Int'L Affairs, Vol 2, Issue 1 (2019)

Impact of Social Media on National ......

contracts, job seekers are asked to pay a sum in advance, under the disguise of a registration fees (Web Desk in SCI-TECH, 2014).

Another case can be dated back to the year 2012. During the month of May in 2012, in Islamabad, a businesswoman had lost somewhere around Rs 450,000 from her bank account by means of an e-banking fraud. As she inquired about her account, she realized that all the money in her account had been withdrawn and when she consulted the branch manager, he claimed that the money had been transferred through e-banking. The mobile number through which the transaction was done, however, did not match the one that she had provided at the time of opening her account. She was further afraid to transfer any cash to her account in case the fraud made a transaction once again (Junaidi, 2012).

While the Government of Pakistan has taken numerous steps to making social media as safe for the people as it is possible, we should consider every act thoroughly before taking a decision as this not only affects us but as the people around us and in turn, our national security in peril.

\section{A POSITIVE OUTLOOK}

Although in hindsight we have a strong argument in favor of the negative impacts of social networking towards the security of everyone, from individuals to entire governments, as seen from all our examples. There is nevertheless a flip side to this argument, and with that in mind, we move on towards the positive contributions that social networking has brought us.

As from the cases of several research articles and studies, there are a number of ways that can be used to potentially enhance the governing body of a country through social media albeit it requires a strong guideline into its approach of implementation. Arguably, the legal system has not evolved as fast as social media, and having not been caught up, imposing proper rules and regulation, which are necessary to avoid the conflicts and threats that have been discussed up until now, is difficult and needs to be understood and researched properly first, without which reminiscent 


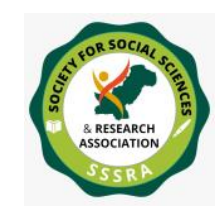

Pak. Journal of Int'L Affairs, Vol 2, Issue 1 (2019)

Impact of Social Media on National ......

problems are destined to follow, cyberattack and etc. (Vela, Martinez, \& Reyes, 2011)

Regardless, it is apparent that there is a huge inherent possibility in its utilization if it's tapped properly and channeled through effective infrastructure.

\section{OPPORTUNITIES}

The potential lies in transformative ways as to how individuals and organizations can relate to each other. In the case of the government, it can utilize this tool as a resource to establish power relationships among citizens and organizations towards creating a more open government. Facilitating the existence of more transparent government and stronger democracies, is arguably possible through these social media applications. (Vela, Martinez, \& Reyes, 2011).

It can also be utilized to make a new government system, similar to how many private organizations have found new ways to create competitive advantages through social media, such as crowd sourcing and even business models. (Vela, Martinez, \& Reyes, 2011).

It is rudimentary to take into notice how an entire society has now been shaped up due to the emergence of this form of technology. Although this has yet to be utilized by governments there are a huge array of versatile opportunities with which this can be utilized. (Bugshan, Hajli, Lin, Featherman, \& Cohen, 2014).

Today's generation has become accustomed to easy solutions to their needs. There are several incongruities to this, meaning there are several missed opportunities in part of the government which are apparent when we realize that on one hand consumers have grown expectations for fast solutions to their problems, where online shopping has generally started to establish itself as a shortcut to product purchases from, but not limited to, high end vehicles to even groceries now, private online companies have 


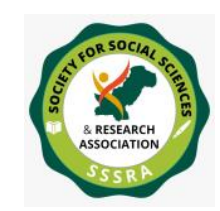

Pak. Journal of Int'L Affairs, Vol 2, Issue 1 (2019)

Impact of Social Media on National ......

readily established themselves as inherent replacement solutions to previous hassling commutes to stores and markets. (Ressler, 2016).

With a consumer base so much inclining towards reliance on these solutions which can be accessed from their homes, it gives a stark contrast to the experience they endure with government. Forms, cash payments, appointments, office hours from 9am to $5 \mathrm{pm}$ and etc. and clashes with the standards being set forth with what society has come to expect from its organizations. (Ressler, 2016).

Which leads to dissemination of information, where people have an easier time comparing hotels than public schools, restaurants rather than hospitals. This shows the severity of this missed opportunity, regardless of the risks involved, for increasing civic engagement and improve the lives of people it serves. (Ressler, 2016).

Some US local governments have found it to be quite effective and useful a tool, whether for establishing a business or renewing driving licenses. Although it has been noted that there are five key factors that must be noted and taken into account.

\section{SCALE}

A social network has value because many people sign up for it, similarly websites are more influential when more people read them. Hence, the services provided by the governments need a substantial audience for a substantial impact. A new app for paying bills, will only be more effective if more people are actually using it than not. Impact must not be measured in thousands but much higher. (Ressler, 2016).

\section{MESHING ONLINE AND OFFLINE EFFORTS}

To get a higher number of people signed up for snow emergency alerts, the city of Minneapolis advertises its subscription options of GovDelivery alerts on the billboards, on its social media accounts and in mailing. This 


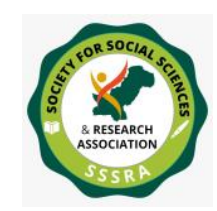

Pak. Journal of Int'L Affairs, Vol 2, Issue 1 (2019)

Impact of Social Media on National .......

helps in one cohesive message used to get residents to sign up for these alerts so they're aware of the latest parking restrictions. (Ressler, 2016).

\section{ACCOUNTS CONNECTING SEAMLESSLY}

The government accounts of citizens should connect seamlessly, for all too often there are separate accounts for individual tasks such as taxes, bills, paying parking tickets etc. and there is no coherent logic to the internal structure of the services. (Ressler, 2016).

\section{SMART SEGMENTATION}

Governments must segment and target their audience to attain better engagement and conversion. Communications tailored specifically to audience interests are more relevant, making it more likely in capturing attention and engaging citizens in initiatives of value. (Ressler, 2016).

The city of Louisville offers pick up reminders of junk to its residents through GovDelivery, through segmentation by location, to coordinate sanitation services better. With more than 12,000 households signed up for this service, receiving texts one week to one day before the scheduled curbside pickup of junk. With this proactive approach of communicating junk pickups with residents, Louisville has increased its efficiency in its call center, the calls to its 311 center regarding pick up dates has been cut by $43 \%$ since 2013 . (Ressler, 2016).

The state of Michigan uses audience data and targeted campaigns to grow the number of applications of foster parents.

The Florida Fish and Wildlife Conservation Commission sends reengagement campaigns promoting new programs, topics of interests, or services to existing subscribers quarterly. (Ressler, 2016).

\section{INFLUENCERS}




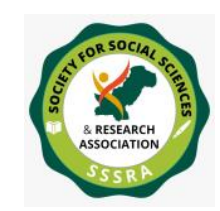

Pak. Journal of Int'L Affairs, Vol 2, Issue 1 (2019)

Impact of Social Media on National ......

Governments should tap in the "Viral Effect" which is created by giving the right message to the right people's hands. A 2014 Pew Research study showed less than $30 \%$ of adults completed government services that were common digitally, mostly because they were unaware of the digital facilities available to them, so finding key influencers who would drive the message across is arguably helpful. (Horrigan \& Rainie, 2015).

King County, Washington, determines cross-promotional campaigns people may respond well to by leveraging insights into the top sharers of digital content, that is, a citizen who is highly engaged in emails from a school district is more likely to give a good response to a targeted request for volunteering activities. (Ressler, 2016).

But all these opportunities are a bit further down the line, all possibilities discussed here are a benchmark set by other governments that our government can hope to attain with a pretty good guideline to follow. These are all assumptions based around the booming IT sector of our country, and hence measures to utilize such incentives will perhaps be quite useful for not only big city governments but on the whole as well. But it must be taken into account that most of the above examples are services proposed by the integration of Web 2.0 in the systems of governmental policies, Web 2.0 is the second stage in the development of the Internet, it is heavily characterized by changes in web pages from static to dynamic or basically user-generated content fortifying a growth in social media, basically tailored responses to what users need and want. This level of integration is not yet possible in our local government but again it is a goal towards which it can go.

\section{HEALTH CARE}

E-health is a tool that involves data and use of communication technology, particularly over the internet, to enhance provisions of health care (Eng, 2001). The definition includes the corresponding use disciplines concerning the use of different technologies and information in health care (Naeuhauser \& Kreps, 2003) which involves the connection between the 


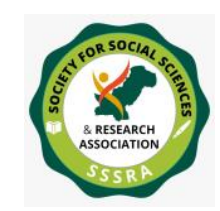

Pak. Journal of Int'L Affairs, Vol 2, Issue 1 (2019)

Impact of Social Media on National ......

"social structure and the new technological paradigm within the health care systems" (Lupianez-Villanueva, Mayer, \& Torrent, 2009).

The findings from a research (Bugshan, Hajli, Lin, Featherman, \& Cohen, 2014) provided highly inductive nodes towards ascertaining that empowering the health care industry in the new development of the Internet has a significant positive impact leading to a better level of patient care and better patient satisfaction.

The study managed to show that the participants gained more satisfaction by receiving online information, advice and experiences from other users. (Bugshan, Hajli, Lin, Featherman, \& Cohen, 2014).

By building social communities for patients on social media, it is empowering them to not only share their personalized health treatment and information but also to seek them from others facing the same thing.

For patients seeking help online social media has been seen to provide strong social support for them. Online health care has two dimensions which are informational support and emotional support. (Bugshan, Hajli, Lin, Featherman, \& Cohen, 2014).

Some relevance of using social media towards healthcare can be apprehended through the context of current examples in our own government.

A research conducted in Lahore, Impact of Social Media Marketing on Health Awareness in Lahore, concluded that relevant findings demonstrated a positive relation between health awareness among people and social media and that its role is 'commendable' towards this goal. The study was conducted from data obtained from 369 people within Lahore. (Sajjad, Akhtar, \& Imdad Ullah, 2015).

The basic aspect of the research was to elaborate on the significance of relevant information, credible information and confidence in information, towards a positive significant effect on Social Media Marketing and that in 


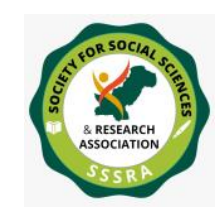

Pak. Journal of Int'L Affairs, Vol 2, Issue 1 (2019)

Impact of Social Media on National ......

affect garnered awareness for healthcare. It is already established in the study that Social Media Marketing is attributed with garnering awareness for healthcare, the study conducted was to infer whether the three factors, as stated above, were relevant towards reinforcing this fact. (Sajjad, Akhtar, \& Imdad Ullah, 2015).

Lahore being the capital of the province of Punjab, has a population of around 10 Million and everyone in the city requires proper and equal healthcare services. Being well developed and a rapidly progressive city the number of clinics and hospitals, in turn facilitating Doctors, Nurses and Pharmacists with providing healthcare services and awareness to the people. Specific health problems can be addressed through social media, to the expansive population with the variety of groups such as bankers, teachers, industrial workers, laborers and etc. about diseases, recent and impending risk factors and emergency situations enabling them to get knowledge and to be educated to manage situations such as natural disasters. (Hussain \& Subramoniam).

With the potential to highlight not only health issues but also enhance communication to the organizations and individuals, social media, helps facilitate to change health behavior of the people by enhancing mobilization of communication of among people and communities.

Medicinal associations have taken the route of social media such as inaugurating verified official pages on Facebook and Twitter to promote a healthy source of relevant information in diseases, treatments and etc. Local Doctors have now taken to social media for providing information on high probability of diseases in those areas where traditional resources cannot be utilized in providing information. And, in turn, people have and can share valuable information on chronic disease and diet plans. Patients have in essence evolved to be healthcare information generators where families can now share information regarding a particular ailment or disease with others who have similar conditions. People communicate on several topics on Facebook, Twitter and several other social networking sites, blogs and etc. Professional healthcare experts could gain advantage 


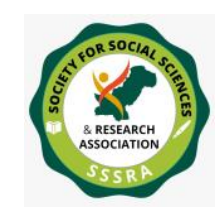

Pak. Journal of Int'L Affairs, Vol 2, Issue 1 (2019)

Impact of Social Media on National ......

by contributing and engaging in the conversation to give feedback and relevant and credible information to the public. (McNab, 2009).

Through questionnaire they established that almost all the participants used social media for healthcare information and purposes and that they implied that the three factors credible information, relevant information and information confidence were relevant attributes that affected the use of such information. (Sajjad, Akhtar, \& Imdad Ullah, 2015).

As it stands the research was limited in scope due to lower budget and henceforth could access only 369 participants. And this limited the scope of the research as it failed to include rural areas, and also those people who would've not been using social media and how they perceived this revolution. The research mainly incorporated working people and students, who by-and-large would be using social media as a daily habit. Even though the scope of the research wasn't broad enough the underlying reveal is the fact that metropolitan cities are primed for this revolution in social media to be used for beneficial healthcare purposes.

\section{WEAPON OF MASS DESTRUCTITON (WMD)}

In a more extreme case social media has been predicted to be highly beneficial in mitigating the aftereffects of Weapons of Mass Destruction. (Kim, 2011).

WMDs can come in different forms, commonly associated by military experts with the rubric CBRNE (chemical, biological, radiological, nuclear and high explosive) which are all designed specifically to maximize fear, disrupt society and above all death. (Kim, 2011).

If a biological weapon is unleashed, a critical facet for the management of such an event would be strategic communication. In situations such as mass casualties, social media and networks as mediums will help with communication solutions not only to institutions of public health but also emergency preparedness to mitigate the consequences of these biological WMDs (Lupianez-Villanueva, Mayer, \& Torrent, 2009). Studies showed 


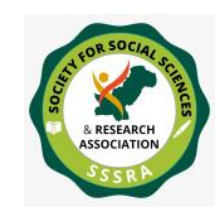

Pak. Journal of Int'L Affairs, Vol 2, Issue 1 (2019)

Impact of Social Media on National ......

that agencies of public health and emergency preparedness are preparing to incorporate new media systems as strategic communication channels, Twitter and Facebook among a few (Kim, 2011).

\section{A PARTIAL INFERENCE}

In a mere incentives point of view, the use of social media in our country has been mainly attributed to entertainment but in realizing a possibility or the prospect if its use in an ubiquitous manner would be beneficial as seen in other governments, whether local, state or national. The appreciation of such a task would be the first step in realizing that not only is there a possibility of such a utilization of this medium in an effective way, but also that there is a definitive need for it under the present conditions of the world.

The problem, however, is still the risks involved with its applications and the necessary capital required for not only its implementation but also the mass awareness that it must ascertain for its usefulness. Like any doubleedged sword, if guided properly, regardless of inhibitions that must be faced, it can give a positive outcome in the long run.

\section{CONCLUSION}

Where nations around world have found social media to be an important factor for their development by providing health care facilities and numerous advantages that the people can redeem through its usage, it also turned out to be a platform that can be used against the wellbeing of the world just as it is used for its wellbeing. Where militant organizations have gotten a hold on how they should present themselves on their social media accounts to attract people for support, people have come together to take the war to social media to bring down those militant groups from those platforms and make them as helpless as possible. Having facilitated many security forces by preventing disastrous acts planned through the social media, it has also facilitated individuals that wait for an opportunity to fraud people gullible enough to get caught in their trap of faux promises. It is no surprise that the world needs to understand the effects of having a 
platform that can prove to be both negative and positive for our national security, be it locally or on a global scale.

\section{REFERENCES}

Agencies. (2015, December 15). US visa process missed Tashfeen's zealotry on social media: report. Retrieved from Pakistan Today: http://www.pakistantoday.com.pk/ 2015/12/14/foreign/us-visa-processmissed-tashfeens-zealotry-on-social-media-report/

Ashford, W. (2013, February). Social media: A security challenge and opportunity. Retrieved June 6, 2016, from ComputerWeekly: http://www.computerweekly.com/feature/Social-media-a-securitychallenge-and-opportunity

Bugshan, H., Hajli, M. N., Lin, X., Featherman, M., \& Cohen, I. (2014). Social Media for developing healthcare services. Quantitative Market Research: An International Journal, 17(3), 283-296.

Cullina, M. (2012, May 10). 9 Alarming Statistics About Identity Theft. Retrieved June 6, 2016, from IDT911: http://idt911.com/education/blog/9alarming-statistics-about-identity-theft

Eng.Thomas R. (2001). The EHealth landscape: a terrain map of emerging information and communication technologies in health and health care. Retrieved from http://www.informatics-review.com/thoughts/rwjf.html 


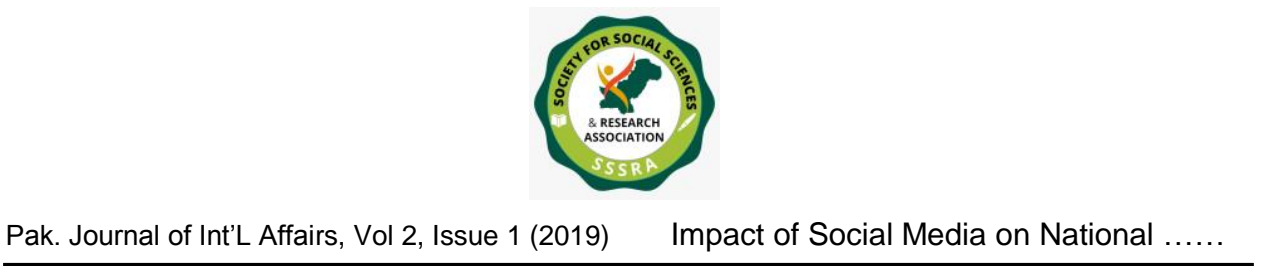

Engel, P. (2015, December 17). Here's the ISIS message the female San Bernardino shooter posted on Facebook during the attack. Retrieved from Business Insider: http://www.businessinsider.com/isis-message-tashfeenmalik-posted-on-facebook-during-attack-2015-12

Haider, M. (2015, December 10). Al-Huda, Tashfeen, and the massacre. Retrieved May 10, 2016, from Dawn: http://www.dawn.com/news/1225251

Horrigan, J. B., \& Rainie, L. (2015). American's Views on Open Government Data. Pew Research Center. Retrieved from http://www.pewinternet.org/2015/04/21/open-government- data/

Hussain, M. N., \& Subramoniam, S. (n.d.). Role of Social Media in Modern Healthcare . Infosys Labs Briefings .

ID Theft Cases: A Few Examples. (2015). Retrieved June 3, 2016, from Identity-Theft-Scenarios: scenarios.com/identity-theft-stories/cases/ http://www.identity-theftJunaidi, I. (2012, May 22). Woman loses Rs450,000 to 'fraud'. Retrieved from Dawn: http://www.dawn.com/news/720356/woman-loses-rs450000to-fraud

Kim, A. C. (2011, December). Potential Benefits of Social Media in A Weapons of Mass Destruction (WMD) Event. A Thesis Presented to the Faculty of the Graduate School University of Missouri, 5-27. Missouri.

Lupianez-Villanueva, F., Mayer, M., \& Torrent, J. (2009). Opportunities and challenges of Web2.0 within the health care systems: An empirical exploration. Informatics for health and social care, 34(3), 117-126.

Man arrested for supporting banned outfits on social media. (2016, April 27). Retrieved from Pakistan Today: http://www.pakistantoday.com.pk/2016/04/27/city/islamabad/manarrested-for-supporting-banned-outfits-on-social-media/ 


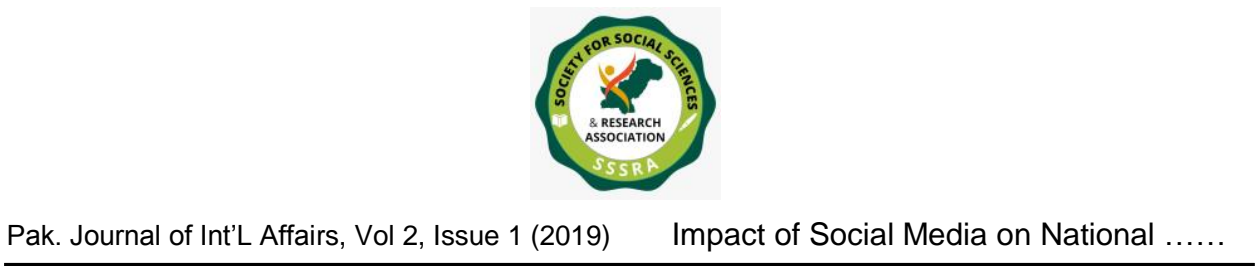

McNab, C. (2009). What Social Media Offers to Health Professionals and Citizens . Bull World Health Organ, 87(8), 566.

Mortimer, C. (2016, January 29). Tareena Shakil guilty: Woman who took toddler son to Syria to join Isis convicted. Retrieved from Independent: http://www.independent.co.uk/news/uk/crime/tareena-shakil-woman-whotook-her-toddler-son-to-syria-to-join-isis-convicted-a6842386.html

Naeuhauser, L., \& Kreps, G. (2003). Rethinking communication in the ehealth era. Journal of Health Psychology, 8(1), 7-23.

Ohlheiser, A. (2015, November 17). What you need to know about Anonymous's 'war' on the Islamic State. Retrieved from Washington Post: $\quad$ https://www.washingtonpost.com/news/theintersect/wp/2015/11/17/what-you-need-to-know-about-anonymouss-waron-the-islamic-state/

Ressler, S. (2016, January 12). How Local Governments Are Using Technology to Serve Citizens Better. Harvard Business Review. Retrieved from https://hbr.org/2016/01/how-local-governments-are-usingtechnology-to-serve-citizens-better/

Reuters. (2016, May 31). Spain arrests Pakistani man for 'promotion of militancy' via social media. Retrieved from Dawn: http://www.dawn.com/news/1261831/spain-arrests-pakistani-man-forpromotion-of-militancy-via-social-media

Sajjad, M., Akhtar, S., \& Imdad Ullah, M. (2015). Impact of Social Media Marketing on Health Awareness in Lahore. Pakistan Journal of Social Sciences (PJSS), 35(1), 335-345.

Singer, P., \& Brooking, E. (2015, December 11). Terror on Twitter. Retrieved from Popsci: http://www.popsci.com/terror-on-twitter-how-isisis-taking-war-to-social-media 
Vela, S. P., Martinez, I. G., \& Reyes, L. F. (2011). Social Media in the Public Sector: Perceived Benefits, Costs and Strategic Alternatives. Proceedings of the 12th Annual International Digital Government Research Conference: Digital Government Innovation in Challenging Times, College Park, Maryland, USA.

Web Desk in SCI-TECH, S. M. (2014, September 20). FIA arrests four fraudsters in over Rs 200m Internet jobs scam. Retrieved from Aaj TV: http://aaj.tv/2014/09/fia-arrests-four-fraudsters-in-over-rs-200m-internetjobs-scam/

Weston, G. (2011, February 16). Foreign hackers attack Canadian government. Retrieved from CBC: http://www.cbc.ca/news/politics/foreign-hackers-attack-canadiangovernment-1.982618

Yusufzai, A. (2016, January). State of Social Media in Pakistan in 2016. Retrieved from Pro Pakistani: http://propakistani.pk/2016/01/26/state-ofsocial-media-in-pakistan-in-2016/ 